\title{
Androgen receptor as potential therapeutic target in metastatic endometrial cancer
}

\author{
Ingvild Løberg Tangen ${ }^{1,2}$, Therese Bredholt Onyango ${ }^{1,2}$, Reidun Kopperud ${ }^{1,2}$, Anna \\ Berg $^{1,2}$, Mari K. Halle ${ }^{1,2}$, Anne M. Øyan ${ }^{3,4}$, Henrica M.J. Werner ${ }^{1,2}$, Jone Trovik ${ }^{1,2}$, Karl \\ Henning Kalland ${ }^{3,4}$, Helga B. Salvesen ${ }^{1,2, *}$, Camilla Krakstad 2,5,* \\ ${ }^{1}$ Centre for Cancer Biomarkers, Department of Clinical Science, University of Bergen, Norway \\ ${ }^{2}$ Department of Gynecology and Obstetrics, Haukeland University Hospital, Norway \\ ${ }^{3}$ Centre for Cancer Biomarkers, Department of Clinical Medicine, University of Bergen, Norway \\ ${ }^{4}$ Department of Microbiology, Haukeland University Hospital, Norway \\ ${ }^{5}$ Centre for Cancer Biomarkers, Department of Biomedicine, University of Bergen, Norway \\ *These authors contributed equally to this work
}

Correspondence to: Camilla Krakstad, email: camilla.krakstad@uib.no

Keywords: androgen receptor, endometrial cancer, biomarker, survival

Received: April 06, $2016 \quad$ Accepted: June 13, $2016 \quad$ Published: June 30, 2016

\section{ABSTRACT}

Purpose: The expression and involvement of estrogen (ER) and progesterone receptor (PR) is extensively studied in endometrial cancer. Androgen receptor (AR) is a hormone receptor less studied in female cancers, and we here aim to investigate the expression level of AR in endometrial cancer precursor lesions, primary tumors and metastases, and its potential as therapeutic target.

Results: Expression of AR was observed in $93 \%$ of hyperplasias, but only in $41 \%$ of non-endometrioid tumors. Compared to estrogen and progesterone receptor AR is more commonly expressed in metastatic lesions, and AR status is discordant in primary and metastatic lesions in a large proportion of cases. AR protein level was significantly associated with survival $(P<0.001)$, and a calculated AR to ERa ratio identified a subgroup of patients with particular poor outcome. The anti-androgen enzalutamide may have a growth inhibitory effect in endometrial cancer cells based on experiments with primary endometrial tumor cells.

Materials and Methods: 718 primary endometrial cancers and 298 metastatic lesions (from 142 patients) were investigated for expression of AR in relation to survival, clinical and histopathological data. Protein levels were investigated by immunohistochemistry and reverse phase protein array; mRNA levels by DNA oligonucleotide microarray. The effect of androgen stimulation and inhibition was tested on primary endometrial tumor cells.

Conclusions: A large proportion of metastatic endometrial cancer lesions express AR, which may be a potential target in these patients. Treatment targeting AR may be of particular benefit in patients with high AR levels compared to ERa levels.

\section{INTRODUCTION}

Endometrial cancer is the most common gynecological malignancy in the Western countries [1]. Little progress has been made in development of treatment options over the past decades. This, combined with a rising incidence, has resulted in an increased number of deaths caused by the disease [2]. Although patients with localized disease have a good prognosis, prognosis is poor for patients with recurrence or metastatic disease at diagnosis and treatment options are few [3]. To improve treatment of this patient group, both the identification of new treatment targets, and identification of potent biomarkers to aid patient stratification are vital.

Traditionally, endometrial cancers have been divided into two groups. Type I, accounting for approximately 
$80 \%$ of cases, is associated with endometrioid histology, low stage and grade, good prognosis and estrogen dependency [3, 4]. Type II tumors are associated with nonendometrioid histology, high stage and grade and poor prognosis [3]. The majority of endometrial cancers are hormone dependent, and hormonal dysregulation is linked to disease development and progression [5]. The role and expression of estrogen and progesterone receptors (ER $\alpha$ and PR) in endometrial cancer have been extensively studied [5]. ER $\alpha$ and/or PR positivity in primary tumors is associated with well-differentiated lesions and more favorable prognosis $[6,7]$. Hormonal therapy targeting both PR and ER $\alpha$ is used in treatment of endometrial cancer. The response rate to such treatments is usually low [8], however, patients expressing hormone receptors have been shown to be more sensitive to hormonal therapy [2].

Androgen receptor (AR) is a hormone receptor less studied in endometrial cancer, although a target for treatment in other cancers $[9,10]$. It is expressed in several tissues, including the uterus, where its role is largely unknown $[10,11]$. In males, aberrant androgen signaling is central to initiation and progression of prostate cancer $[12,13]$. Treatment targeting AR or androgen synthesis is therefore one of the main therapeutic elements in patients with hormone dependent prostate cancer [9]. Recently, also in breast cancer treatment, targeting AR has been suggested beneficiary for specific subgroups of patients [10].

Given the similarities of breast and endometrial cancers, exploring AR expression in endometrial cancer might reveal new therapeutic strategies. Additionally, AR status in malignant endometrial lesions may be related to clinical phenotype and could represent a novel biomarker for prognosis.

\section{RESULTS}

\section{AR is expressed in the majority of hyperplasias and primary endometrial cancer lesions}

The expression pattern of AR was investigated in relation to aggressiveness of endometrial cancer. AR staining was predominantly nuclear, and only staining in glandular tissue was scored (Figure 1A and 1B). Precursor lesions were included to investigate if there was a change in expression from the pre-malignant to the malignant stage. Hyperplasias had the highest level of AR expression. Of the 69 hyperplasias evaluated, 93\% (64 patients) expressed AR. In primary tumors the percentage of lesions with AR expression decreased significantly from $74 \%$ to $53 \%$ from endometrioid grade 1 to grade 3 tumors respectively and further to $41 \%$ in non-endometrioid tumors (Figure 1C). This pattern was reflected when assessing mRNA levels (Figure ID), and there was significant overlap between AR expression evaluated by IHC and AR mRNA expression (Supplementary Figure 1).

\section{$A R$ is frequently expressed in metastatic lesions of endometrial cancer}

As for most cancers, metastatic endometrial cancers have high mortality and few treatment options. Characterization of metastatic lesions is therefore highly important, especially considering molecular targets with existing therapeutics. Expression was investigated in 298 metastatic lesions from 142 patients (Supplementary Table 1). We observed that a high number of the metastatic lesions express AR. For patients with corresponding metastatic lesions $\mathrm{AR}, \mathrm{PR}$ and $\mathrm{ER} \alpha$ was expressed in $48 \%, 61 \%$ and $52 \%$ of the primary tumors respectively (Figure 2A, 2D and 2G). In metastases from hormone receptor (AR, PR or ER $\alpha$ ) positive primary tumors, expression was retained in at least one metastatic lesion in $71 \%$ of cases for AR, $58 \%$ for PR and $64 \%$ for ER $\alpha$ (Figure 2B, 2E and 2H). Also $44 \%$ of patients defined to have lost expression of AR in the primary tumor expressed $\mathrm{AR}$ in at least one metastatic lesion (Figure 2C). For ER $\alpha$ and PR this was only $20 \%$ (Figure $2 \mathrm{~F}$ and $2 \mathrm{I}$ ). AR, PR and $\mathrm{ER} \alpha$ were investigated in individual metastases to compare expression patterns. A high degree of heterogeneity in hormone receptor expression was observed both in metastases from AR positive primary tumors (Figure 2J) and AR negative primary tumors (Figure 2K). 39\% of the metastatic lesions expressing AR had low expression of $\mathrm{ER} \alpha$.

\section{Expression of AR is associated with good survival}

Loss of AR was significantly associated with established features of aggressive tumors, such as high FIGO stage $(P<0.001)$, non-endometrioid histology $(P<0.001)$ and high grade within the endometrioid subgroup $(P=0.001)$ (Table 1$)$. The relation between disease specific survival and AR expression was investigated using groups with high and low expression of AR as defined in the method section. AR loss associated with shorter disease specific survival both in the whole population (Figure 3A) and within the subgroup of patients with disease confined to the uterus, FIGO stages I/II (Figure 3B). In multivariate survival analyses AR did not demonstrate independent prognostic impact when adjusting for factors with known prognostic value (age, histologic type and grade) ( $p=0.12$, data not shown), indicating that loss of AR may not add additional information regarding survival when used in a clinical setting. Still, the high number of primary tumors and metastatic lesions with intact expression of AR could point to an unexploited potential for treatment targeting AR in endometrial cancer, and it might be of particular interest in specific subgroups as observed for other cancer types. 


\section{High AR to ERa ratio identifies patients with particularly poor survival}

Based on previous findings in breast cancer, we hypothesized that also for endometrial cancer, the effect of AR signaling may be influenced by the presence of ER $\alpha$. Interestingly, the patients with the highest calculated AR to $E R \alpha$ ratio (based on RPPA data) had significantly worse survival, both in the whole population (Figure 4A) and in FIGO stages I/II (Supplementary Figure 2A). A high ratio was also significantly associated with established features of aggressive tumors (Supplementary Table 2). In a subpopulation with especially long follow up, a high AR to ER $\alpha$ ratio, calculated based on mRNA levels, also identified a patient group with significantly worse survival compared with patients with a low AR to ER $\alpha$ ratio, both in the whole population (Supplementary Figure 2B) and in FIGO stages I/II (Supplementary Figure 2C).

The underlying mechanisms involved were explored by investigating transcriptional alterations related to the high AR to ER $\alpha$ ratio group. In GSEA analysis several of the top ranked GO gene sets enriched in the high AR to $\mathrm{ER} \alpha$ ratio group were associated with cell cycle regulation (Supplementary Table 3). This finding was supported by the significantly higher proliferation identified in patients with high AR to ER $\alpha$ ratio, assessed both by high cell cycle progression (CCP) score and high proliferation cell nuclear antigen (PCNA) levels (measured by Reverse Phase Protein Array) (Figure 4B and 4C).

To explore if transcriptional alterations related to the high AR to ER $\alpha$ ratio could suggest new targets for treatment, Connectivity map was queried for drug signatures negatively correlated with the gene expression profile of tumors with a high AR to ER $\alpha$ ratio. Compounds targeting phosphoinositide 3-kinase (PI3K)/mammalian target of rapamycin (mTOR) pathway were among the top ranked, along with HSP90 inhibitors, known to disrupt hormone binding and hormone receptor stability [14], the AR inhibitor Resveratol $[15,16]$ and a CDK inhibitor [17] (Supplementary Table 4). These findings suggest that drugs targeting proliferation and anti-androgen treatment could be potential treatment options for the high AR to $E R \alpha$ ratio patient subgroup in particular. Supporting this, preliminary results in short-term cultures of AR positive (defined by IHC staining of patient biopsy) primary endometrial tumor cells, proliferation was significantly inhibited by the anti-androgen enzalutamide, and there was a tendency to increased proliferation after stimulation with the synthetic androgen R1881, although not statistically significant. No effect was seen in AR negative or focal positive cells (data not shown).

\section{DISCUSSION}

Several studies have demonstrated that ER $\alpha$ and PR status are important prognostic biomarkers, also predicting response to anti-hormonal therapy in endometrial cancer $[6,7]$. For AR available data is more limited. It is still unsettled if AR could predict outcome and also, whether there is a role for androgen targeting drugs in endometrial cancer treatment. The published studies are few with low number of included patients, leaving inconclusive results [18-24]. In the present study, to date the largest and most comprehensive study with extensive clinical annotation and samples ranging from precursors through primary to metastatic endometrial carcinoma lesions, we find that precursor lesions and well-differentiated primary tumors have the highest level of AR, with a gradual
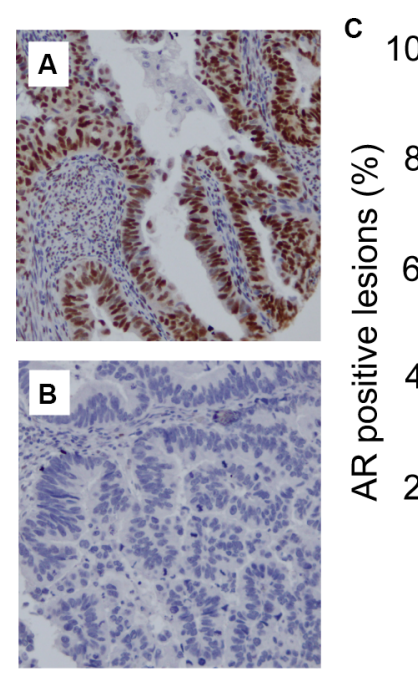
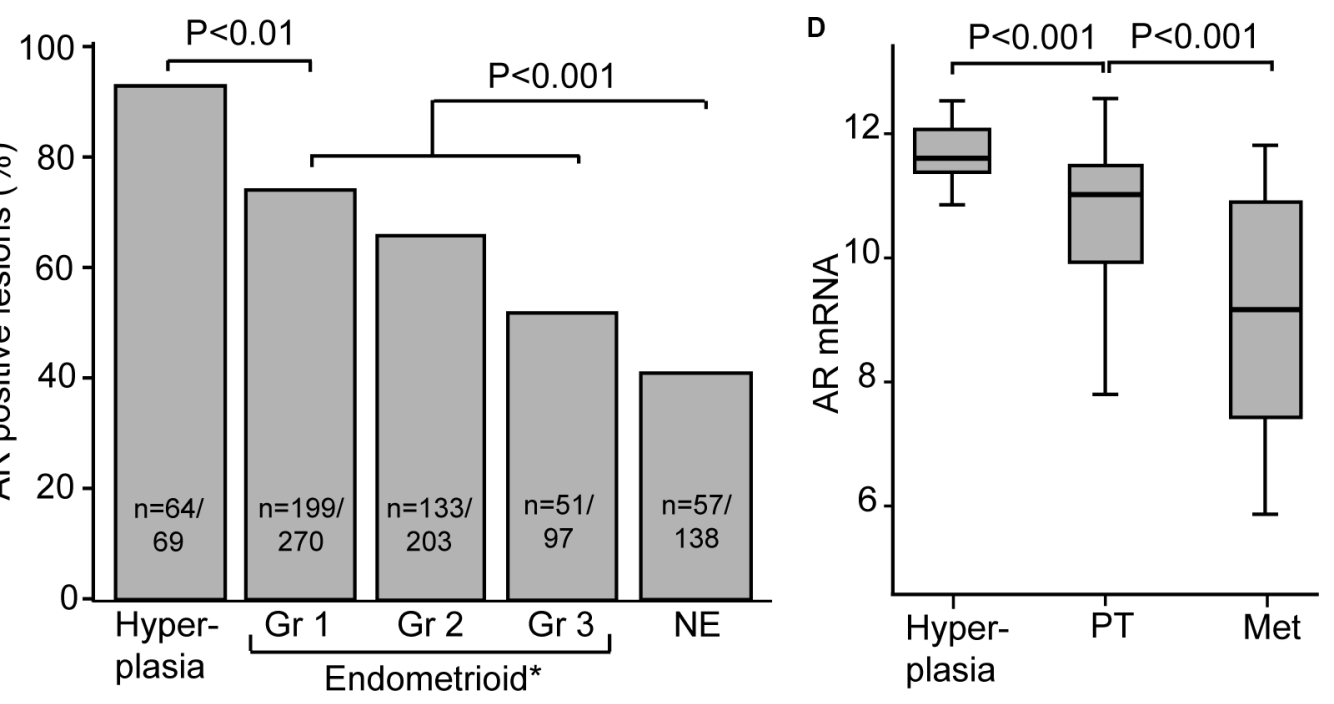

Figure 1: AR expression decreases with dedifferentiation. AR expression in glandular cells was scored, with strong AR immunohistochemical staining shown in (A) and AR loss in (B). Both AR protein level (C) and mRNA (D) level decreased with dedifferentiation. Abbreviations: AR: androgen receptor, Gr: grade, NE: non-endometrioid, PT: primary tumor, Met: metastases, *Information on grade missing for 10 patients included in the study (7 AR positive and 3 AR negative) 


\section{Table 1: Clinico-pathological variables related to androgen receptor (AR) status in endometrial cancer patients}

\begin{tabular}{|c|c|c|c|}
\hline & & & \\
\hline Variable & Positive $n(\%)$ & Loss $n(\%)$ & $P$-value \\
\hline Age & & & 0.7 \\
\hline$<66$ & $229(63)$ & $135(37)$ & \\
\hline$\geq 66$ & $218(62)$ & $136(38)$ & \\
\hline FIGO-09 stage & & & $<0.001$ \\
\hline I-II & $396(66)$ & $204(34)$ & \\
\hline III-IV & $51(43)$ & $67(57)$ & \\
\hline Histologic type & & & $<0.001$ \\
\hline Endometrioid & $386(67)$ & $188(33)$ & \\
\hline Adenosquamous & $4(67)$ & $2(33)$ & \\
\hline Clear cell & $7(25)$ & $21(75)$ & \\
\hline Serous papillary & $36(55)$ & $29(45)$ & \\
\hline Carcinosarcoma & $13(41)$ & $19(59)$ & \\
\hline Undifferentiated/other & $1(7)$ & $12(92)$ & \\
\hline Histologic grade* & & & 0.001 \\
\hline Grade $1 / 2$ & $329(70)$ & $140(30)$ & \\
\hline Grade 3 & $50(53)$ & $45(47)$ & \\
\hline Metastatic nodes & & & $<0.001$ \\
\hline Negative & $333(65)$ & $176(35)$ & \\
\hline Positive & $28(42)$ & $39(58)$ & \\
\hline Ploidy & & & 0.3 \\
\hline Diploid & $223(64)$ & $128(36)$ & \\
\hline Aneuploid & $59(58)$ & $43(42)$ & \\
\hline PR & & & $<0.001$ \\
\hline Positive & $391(74)$ & $137(26)$ & \\
\hline Negative & $40(26)$ & $115(74)$ & \\
\hline ERa & & & $<0.001$ \\
\hline Positive & $390(78)$ & $113(22)$ & \\
\hline Negative & $42(23)$ & 140 (77) & \\
\hline
\end{tabular}

*only endometrioid, missing information on grade for ten cases.

decrease in AR level with dedifferentiation. This pattern is consistently found using different methods to assess AR levels. Our findings thus appear to be in line with previous smaller studies, reporting AR loss ranging from 11.4\% in endometrioid primary tumors [25] to $79 \%$ in a study including primary tumors of different histological subtypes [26]. A significant association between dedifferentiation and AR loss has also been reported in a small study including 35 patients [27]. In this study we show that also $\mathrm{AR}$ is a prognostic marker in endometrial cancer as earlier well documented for ER $\alpha$ and PR [6, 28-30].

The extensive experience with anti-androgen treatment in prostate cancer makes it attractive for investigation also in other hormone dependent cancers. There are several available anti-androgen treatments with different mechanism of action. The anti-androgen bicalutamide inhibits binding of ligand to the androgen receptor, while enzalutamide, a second generation anti-androgen, inhibits several steps of AR activation. Inhibition of AR signaling can also be achieved through inhibition of ligand synthesis. Abiraterone inhibits the enzyme CYP17 which is necessary for androgen biosynthesis [31]. Although our findings show that AR expression is associated with low grade tumors, it may, analogous to ER $\alpha$, still be a driver for tumor growth and therefore a potential therapeutic target. Our preliminary 


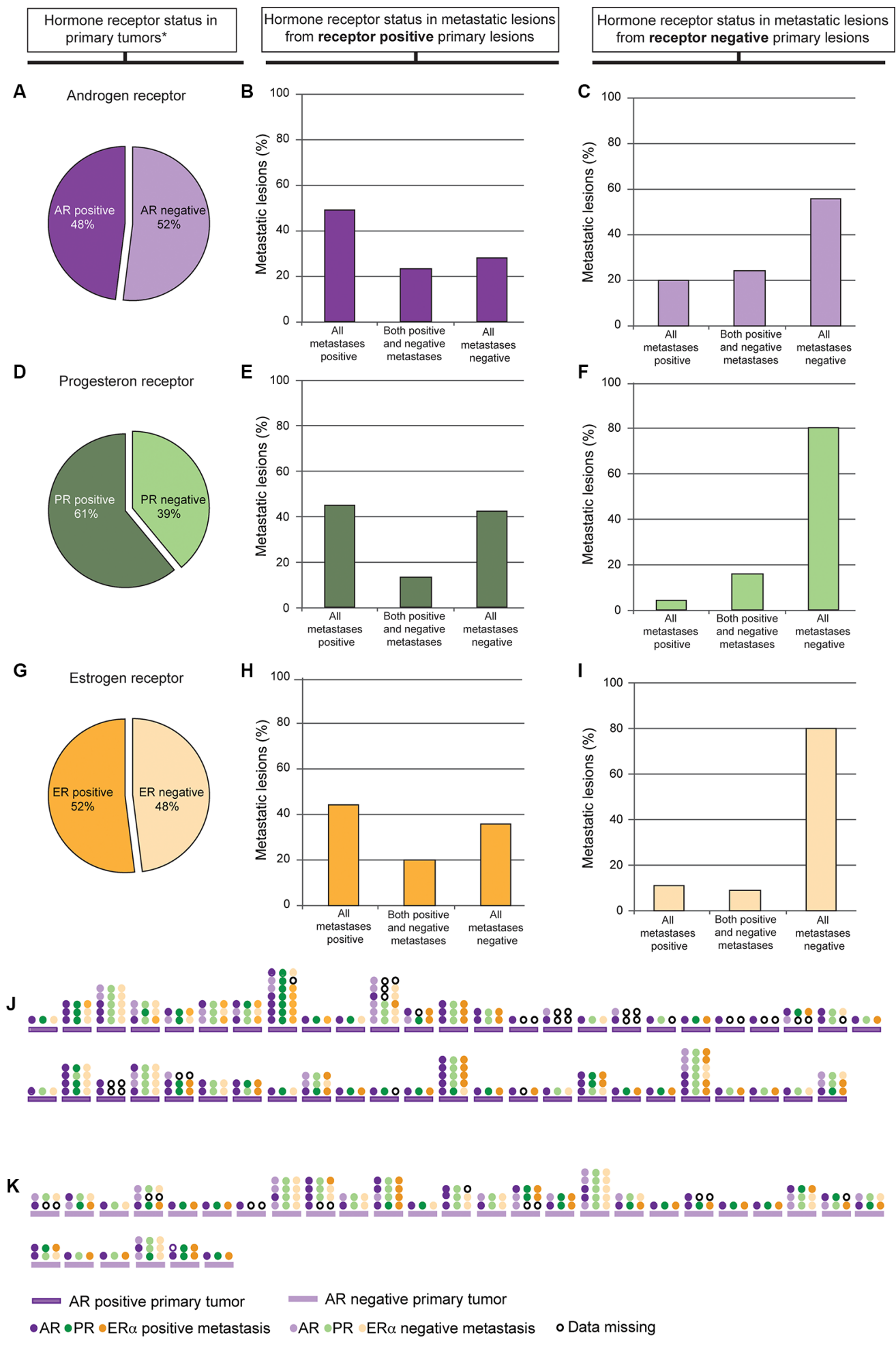

Figure 2: Expression of the individual hormone receptors AR, PR and ER $\alpha$ in metastatic lesions based on its expression in primary tumor. $48 \%$ of the primary tumors with corresponding metastatic lesions were AR positive (IHC score 1-9) (A). Graphs show distribution of AR expression in the metastatic lesions from AR positive primary tumors $(\mathbf{B})$ and AR negative primary tumors $(\mathbf{C})$. $61 \%$ of the primary tumors with corresponding metastatic lesions were PR positive (IHC score 1-9) (D). Graphs show distribution of PR expression in the metastatic lesions from the PR positive primary tumors (E) and PR negative primary tumors (F). $52 \%$ of the primary tumors with corresponding metastatic lesions were ER positive (IHC score 4-9) (G). Graphs show distribution of ER expression in the ER positive primary tumors $(\mathbf{H})$ and ER negative primary tumors (I). Expression patterns in individual metastases from AR positive patients (J) and AR negative patients (K) are shown as AR (purple), PR (green) and ER $\alpha$ (orange) in J and K. One line of circles represents one metastasis, and shows the difference in hormone receptor expression in that specific metastasis. Only patients with one or more AR positive metastases are shown. *Only primary tumors with corresponding metastases included. 

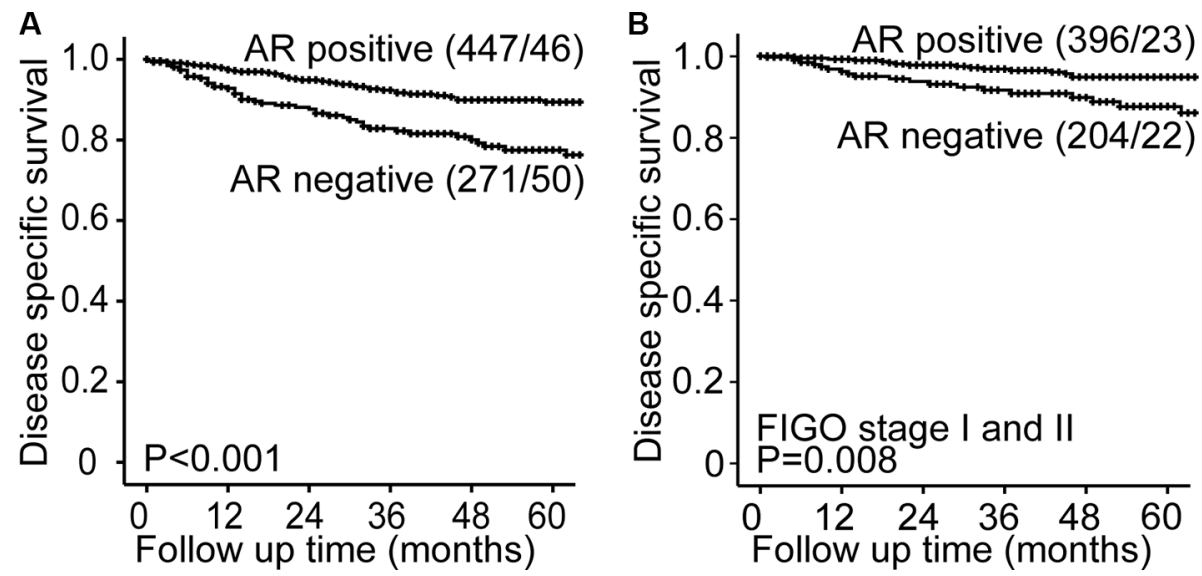

Figure 3: AR status predicts prognosis in endometrial cancer. Endometrial cancer patients with AR expression (scoring index 1-9) have a significantly better survival than patient with AR loss (scoring index 0) both in the whole population (A) and in the subgroup of patients with FIGO stage I and II (B).

A

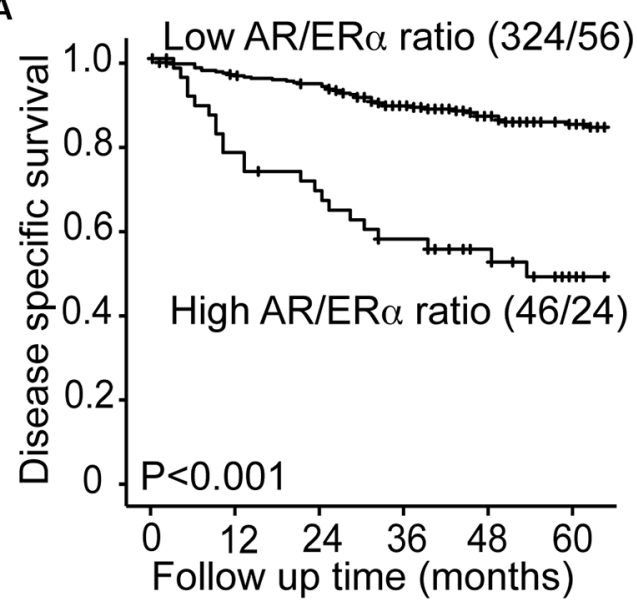

C

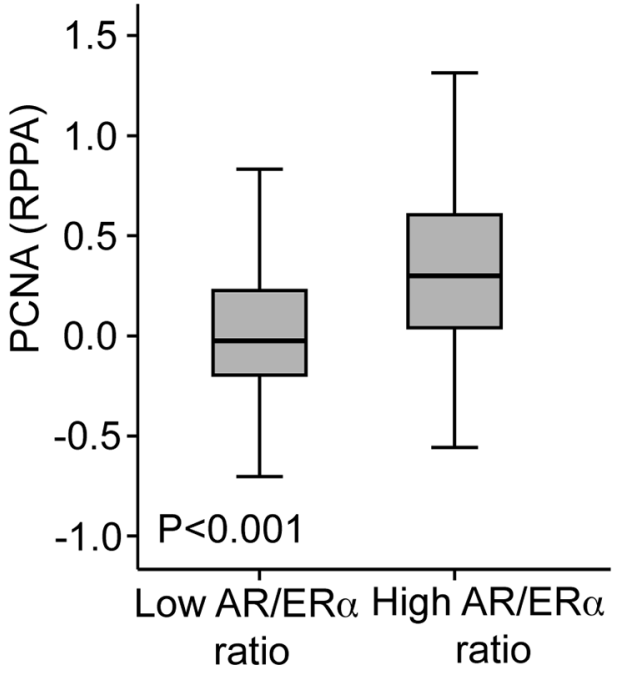

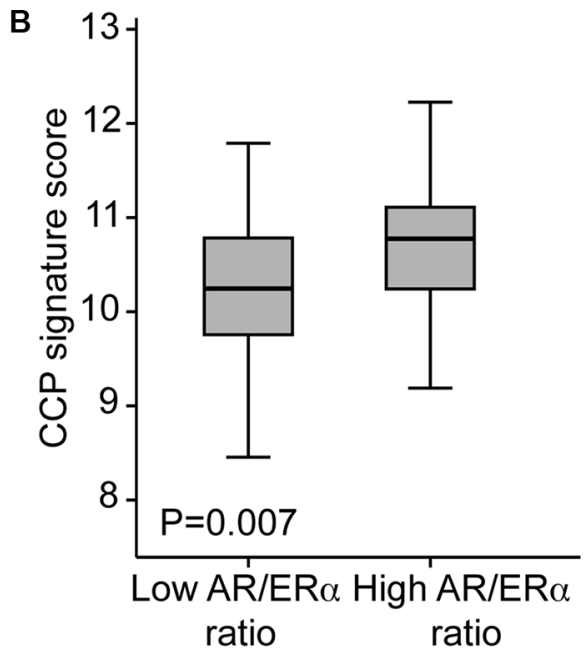

ratio ratio 
results indicate that enzalutamide may inhibit proliferation in AR positive primary endometrial cancer cells. This is an interesting observation that calls for follow-up functional studies. There are few studies investigating the effect of AR signaling on endometrial cells, and the results from these studies are contradictory. Different mechanisms have been suggested by which androgens may exert their effect on the endometrium. The proliferative effects of androgen have been linked to enhancement of EGF action [18], increased expression of genes involved in IGF-1 and Wnt signaling [19] or to endometrial cancer cell proliferation through activation of the oncogene c-myc [20]. These studies are however contradicted by the finding that androgens inhibit proliferation of endometrial cells in vitro $[21,22]$, and several studies on the weakly AR positive endometrial cancer cell line MFE-296 demonstrating growth inhibition by androgen stimulation [23, 24]. These conflicting results could imply different roles for AR at different stages of endometrial cancer and indicate that AR signaling is context-dependent. This is in line with our finding that a subgroup of patients with high AR to $\mathrm{ER} \alpha$ ratio has particularly poor survival, indicating that ER $\alpha$ status may influence the effect of AR. Our findings are also in line with previous observations from breast cancer, where the prognostic value of AR is improved by combining AR and $\mathrm{ER} \alpha$ status $[32,33]$. Cochrane et. al. found that a high AR to $\mathrm{ER} \alpha$ ratio was an independent predictor of disease-free and disease specific survival in breast cancer [34]. Studies are ongoing in breast cancer to investigate the effect of anti-androgen treatment in patients with AR positive tumors with loss of ER $\alpha$ and PR (ClinicalTrials.gov Identifier NCT00468715, NCT01889238). Similar studies in endometrial cancer patients could reveal whether AR could be a potential target also in endometrial cancer patients with high AR to $\mathrm{ER} \alpha$ ratio.

Hormonal treatment targeting ER $\alpha$ and PR is found to be most effective if the hormone receptor is expressed $[2,35]$. Since the expression of these hormone receptors is discordant between primary and metastatic lesions $[6,36]$, investigating the expression status also in the metastatic setting is important. We find that AR is more often expressed in metastatic lesions compared to ER and PR, but also AR expression is discordant in primary and metastatic lesions in a large proportion of cases. Since a large proportion of metastatic endometrial cancers express AR, this may serve as a potential therapeutic target for this patient group, and particularly in the group with a high $\mathrm{AR}$ to $\mathrm{ER} \alpha$ ratio. As there are several available treatments targeting AR, further studies should be conducted to investigate their potential in treatment of endometrial cancer. This study also underlines the need to examine metastatic expression of potential therapeutic targets, as multiple studies have also done concerning other biomarkers and targets [6, 36-38], and clearly demonstrates that the primary tumor is not representative for its metastatic lesions.

\section{MATERIALS AND METHODS}

\section{Patient series}

A population-based patient series was prospectively collected from 2001 to 2015 and included 718 primary tumors from patients diagnosed with endometrial cancer in Hordaland County (Norway). Clinical data were collected as previously described [39] and patients were surgically staged according to the International Federation of Gynecology and Obstetrics (FIGO) 2009 criteria. Samples from precursor lesions (complex atypical hyperplasia) were available from 69 patients and metastasis from 142 patients (in total 298 metastatic lesions). Fresh frozen tissue were investigated for gene expression for 223 patients of which 163 overlapped with formalin fixed paraffin embedded tissue (FFPE). In addition protein expression was investigated in 370 patients by reverse phase protein array (RPPA) where 306 overlapped with FFPE (Supplementary Table 5).

The study has been approved by Norwegian legislation, including the Norwegian Data Inspectorate, Norwegian Social Sciences Data Services and the Western Regional Committee for Medical and Health Research Ethics (REK 2009/2315). Patients gave written informed consent.

\section{Immunohistochemical staining}

Tissue microarrays (TMA) were dewaxed in xylene and rehydrated in graded ethanol series before microwave boiling in target retrieval buffer $(\mathrm{pH} 9)$ for 15 minutes. Staining for AR, ER $\alpha$ and PR expression was performed as previously described $[6,7,40]$. The staining was evaluated using a semi-quantitative system where both intensity and area of positive tumor cells is considered. Staining intensity was graded from 0 (no staining) to 3 (strong staining), and area from 0,1 $(<10 \%), 2(10-50 \%)$ and $3(>50 \%)$. A staining index was calculated as the product of staining intensity and area. For AR and PR, staining index 0 was considered negative, and index 1-9 positive. For ER index 0-3 was defined as low, and 4-9 as high. The method for producing tissue microarrays (TMA) has previously been described and validated $[41,42]$.

\section{Gene expression analysis}

RNA was extracted from fresh frozen tissue from 18 hyperplasias, 174 primary tumors and 42 metastases, and hybridized to Agilent Whole Human Genome Microarrays 44k (Cat. No. G4112F), according to the manufacturer's instruction. The arrays were scanned and normalized as previously described [36]. Gene Ontology (GO) gene sets enriched in different groups were 
investigated with Gene Set Enrichment Analysis (GSEA) using gene permutations and Significance Analysis of Microarray (SAM) as scoring method. The signature score for the cell cycle progression (CCP) signature published by Cuzik et al [43] was calculated as previously described [6]. Connectivity Map [44] was used to search for potential drugs based on differences in gene expression between the high AR to ER $\alpha$ ratio and the AR to ER $\alpha$ ratio group. 23 cases with high ratio $(\geq 1.25)$, and the 41 cases with lowest ratio $(\leq 0.95)$ were included in the analysis. The AR to ER ratio based on mRNA expression was calculated by dividing the AR value with $\mathrm{ER}$ value.

\section{Reverse phase protein array}

Reverse Phase Protein Array (RPPA) was performed for 370 of the primary tumors as previously described $[45,46]$. Slides were stained using antibodies as listed (https:// www.mdanderson.org/education-and-research/resources-forprofessionals/scientific-resources/core-facilities-and-services/ functional-proteomics-rppa-core/index.html). Relative protein levels were determined by fitting each dilution curve with a logistic model ('Supercurve Fitting' http://bioinformatics. mdanderson.org/OOMPA) [47]. Expression levels of AR, $\mathrm{ER} \alpha$ and proliferation cell nuclear antigen (PCNA) were extracted from the whole RPPA dataset. The AR to ER $\alpha$ ratio was calculated by dividing the AR value with ER $\alpha$ value.

\section{Statistical analysis}

Data were analyzed using SPSS version 22 (SPSS Inc, Chicago, IL). Probability $<0.05$ was considered statistical significant. Associations between groups were evaluated using the chi-square test for categorical variables and the Mann-Whitney $U$ test for continuous variables. Univariate survival analysis was performed using the Kaplan Meier (product-limit) method. Date of primary surgery was entry date, and date of death due to endometrial carcinoma was defined as event for estimation of disease specific survival. Survival between groups was compared using the log-rank (Mantel-Cox) test. The Cox proportional hazard regression model was used to evaluate the prognostic impact of AR adjusted for other prognostic parameters. Included in the model was in addition to AR; age, histologic type and grade, all factors with known prognostic impact in endometrial cancer.

\section{ACKNOWLEDGMENTS}

We thank Ellen Valen, Britt Edvardsen, Kadri Madissoo and Bendik Nordanger for technical assistance.

We would like to dedicate this manuscript to Helga B. Salvesen who recently died unexpectedly. She was a dedicated physician and scientist, and a warm and caring person. We will all miss her.

\section{CONFLICTS OF INTEREST}

No potential conflicts of interest was disclosed.

\section{FINANCIAL SUPPORT}

This study was supported by Helse Vest, the University of Bergen, the Norwegian Cancer Society (Harald Andersen Legat), the Research Council of Norway and Bergen Research Foundation.

\section{REFERENCES}

1. Parkin DM, Bray F, Ferlay J, Pisani P. Global cancer statistics, 2002. CA Cancer J Clin. 2005; 55:74-108.

2. Fleming GF. Second-Line Therapy for Endometrial Cancer: The Need for Better Options. J Clin Oncol. 2015; 33:3535-3540.

3. Salvesen HB, Haldorsen IS, Trovik J. Markers for individualised therapy in endometrial carcinoma. Lancet Oncol. 2012; 13:e353-361.

4. Dinkelspiel HE, Wright JD, Lewin SN, Herzog TJ. Contemporary clinical management of endometrial cancer. Obstet Gynecol Int. 2013; 2013:583891.

5. Bender D BT, Leslie KK. Hormones and Receptors in Endometrial Cancer. Proc Obstet Gynecol. 2011; 2:25.

6. Tangen IL, Werner HM, Berg A, Halle MK, Kusonmano K, Trovik J, Hoivik EA, Mills GB, Krakstad C, Salvesen HB. Loss of progesterone receptor links to high proliferation and increases from primary to metastatic endometrial cancer lesions. Eur J Cancer. 2014; 50:3003-3010.

7. Wik E, Raeder MB, Krakstad C, Trovik J, Birkeland E, Hoivik EA, Mjos S, Werner HM, Mannelqvist M, Stefansson IM, Oyan AM, Kalland KH, Akslen LA, et al. Lack of estrogen receptor-alpha is associated with epithelialmesenchymal transition and PI3K alterations in endometrial carcinoma. Clin Cancer Res. 2013; 19:1094-1105.

8. Kokka F, Brockbank E, Oram D, Gallagher C, Bryant A. Hormonal therapy in advanced or recurrent endometrial cancer. Cochrane Database Syst Rev. 2010; CD007926.

9. Harris KA, Small EJ. Hormonal treatment for prostate cancer. Expert Opin Investig Drugs. 2001; 10:493-510.

10. Fioretti FM, Sita-Lumsden A, Bevan CL, Brooke GN. Revising the role of the androgen receptor in breast cancer. J Mol Endocrinol. 2014; 52:R257-265.

11. Gibson DA, Simitsidellis I, Collins F, Saunders PT. Evidence of androgen action in endometrial and ovarian cancers. Endocr Relat Cancer. 2014; 21:T203-218.

12. Gelmann EP. Molecular biology of the androgen receptor. J Clin Oncol. 2002; 20:3001-3015.

13. Heinlein CA, Chang C. Androgen receptor in prostate cancer. Endocr Rev. 2004; 25:276-308. 
14. Vanaja DK, Mitchell SH, Toft DO, Young CY. Effect of geldanamycin on androgen receptor function and stability. Cell Stress Chaperones. 2002; 7:55-64.

15. Harada N, Atarashi K, Murata Y, Yamaji R, Nakano Y, Inui H. Inhibitory mechanisms of the transcriptional activity of androgen receptor by resveratrol: Implication of DNA binding and acetylation of the receptor. J Steroid Biochem Mol Biol. 2011; 123:65-70.

16. Harada N, Murata Y, Yamaji R, Miura T, Inui H, Nakano Y. Resveratrol down-regulates the androgen receptor at the post-translational level in prostate cancer cells. J Nutr Sci Vitaminol (Tokyo). 2007; 53:556-560.

17. Khan SA, Faisal A, Mpindi JP, Parkkinen JA, Kalliokoski T, Poso A, Kallioniemi OP, Wennerberg K, Kaski S. Comprehensive data-driven analysis of the impact of chemoinformatic structure on the genome-wide biological response profiles of cancer cells to 1159 drugs. BMC Bioinformatics. 2012; 13:112.

18. Watson H, Franks S, Bonney RC. Regulation of epidermal growth factor receptor by androgens in human endometrial cells in culture. Hum Reprod. 1998; 13:2585-2591.

19. Nantermet PV, Masarachia P, Gentile MA, Pennypacker B, Xu J, Holder D, Gerhold D, Towler D, Schmidt A, Kimmel DB, Freedman LP, Harada S, Ray WJ. Androgenic induction of growth and differentiation in the rodent uterus involves the modulation of estrogen-regulated genetic pathways. Endocrinology. 2005; 146:564-578.

20. Qiu M, Bao W, Wang J, Yang T, He X, Liao Y, Wan X. FOXA1 promotes tumor cell proliferation through AR involving the Notch pathway in endometrial cancer. BMC Cancer. 2014; 14:78.

21. Rose GL, Dowsett M, Mudge JE, White JO, Jeffcoate SL. The inhibitory effects of danazol, danazol metabolites, gestrinone, and testosterone on the growth of human endometrial cells in vitro. Fertil Steril. 1988; 49:224-228.

22. Neulen J, Wagner B, Runge M, Breckwoldt M. Effect of progestins, androgens, estrogens and antiestrogens on $3 \mathrm{H}$-thymidine uptake by human endometrial and endosalpinx cells in vitro. Arch Gynecol. 1987; 240:225-232.

23. Hackenberg R, Beck S, Filmer A, Hushmand Nia A, Kunzmann R, Koch M, Slater EP, Schulz KD. Androgen responsiveness of the new human endometrial cancer cell line MFE-296. Int J Cancer. 1994; 57:117-122.

24. Hackenberg R, Schulz KD. Androgen receptor mediated growth control of breast cancer and endometrial cancer modulated by antiandrogen- and androgen-like steroids. J Steroid Biochem Mol Biol. 1996; 56:113-117.

25. Ito $\mathrm{K}$, Suzuki $\mathrm{T}$, Akahira J, Moriya $\mathrm{T}$, Kaneko C, Utsunomiya H, Yaegashi N, Okamura K, Sasano H. Expression of androgen receptor and 5alpha-reductases in the human normal endometrium and its disorders. Int $\mathbf{J}$ Cancer. 2002; 99:652-657.

26. Sasaki M, Oh BR, Dharia A, Fujimoto S, Dahiya R. Inactivation of the human androgen receptor gene is associated with $\mathrm{CpG}$ hypermethylation in uterine endometrial cancer. Mol Carcinog. 2000; 29:59-66.

27. Kato J, Seto T. Correlation of androgen receptors with histological differentiation in human endometrial carcinomas. Acta obstetricia et gynecologica Scandinavica. 1985; 64:209-212.

28. Kadar N, Malfetano JH, Homesley HD. Steroid receptor concentrations in endometrial carcinoma: effect on survival in surgically staged patients. Gynecol Oncol. 1993; 50:281-286.

29. Fukuda K, Mori M, Uchiyama M, Iwai K, Iwasaka T, Sugimori H. Prognostic significance of progesterone receptor immunohistochemistry in endometrial carcinoma. Gynecol Oncol. 1998; 69:220-225.

30. Kleine W, Maier T, Geyer H, Pfleiderer A. Estrogen and progesterone receptors in endometrial cancer and their prognostic relevance. Gynecol Oncol. 1990; 38:59-65.

31. Culig Z. Targeting the androgen receptor in prostate cancer. Expert Opin Pharmacother. 2014; 15:1427-1437.

32. Elebro K, Borgquist S, Simonsson M, Markkula A, Jirstrom K, Ingvar $\mathrm{C}$, Rose $\mathrm{C}$, Jernstrom H. Combined Androgen and Estrogen Receptor Status in Breast Cancer: Treatment Prediction and Prognosis in a Population-Based Prospective Cohort. Clin Cancer Res. 2015; 21:3640-3650.

33. Cochrane DR, Bernales S, Jacobsen BM, Cittelly DM, Howe EN, D'Amato NC, Spoelstra NS, Edgerton SM, Jean A, Guerrero J, Gomez F, Medicherla S, Alfaro IE, et al. Role of the androgen receptor in breast cancer and preclinical analysis of enzalutamide. Breast Cancer Res. 2014; 16:R7.

34. Cochrane DR, Bernales S, Jacobsen BM, Cittelly DM, Howe EN, D'Amato NC, Spoelstra NS, Edgerton SM, Jean A, Guerrero J, Gómez F, Medicherla S, Alfaro IE, et al. Role of the androgen receptor in breast cancer and preclinical analysis of enzalutamide. Breast Cancer Res. 2014; 16: R7.

35. Carlson MJ, Thiel KW, Leslie KK. Past, present, and future of hormonal therapy in recurrent endometrial cancer. Int $\mathrm{J}$ Womens Health. 2014; 6:429-435.

36. Krakstad C, Trovik J, Wik E, Engelsen IB, Werner HM, Birkeland E, Raeder MB, Oyan AM, Stefansson IM, Kalland KH, Akslen LA, Salvesen HB. Loss of GPER identifies new targets for therapy among a subgroup of ERalpha-positive endometrial cancer patients with poor outcome. Br J Cancer. 2012; 106:1682-1688.

37. Lindstrom LS, Karlsson E, Wilking UM, Johansson U, Hartman J, Lidbrink EK, Hatschek T, Skoog L, Bergh J. Clinically used breast cancer markers such as estrogen receptor, progesterone receptor, and human epidermal growth factor receptor 2 are unstable throughout tumor progression. J Clin Oncol. 2012; 30:2601-2608.

38. Werner HM, Berg A, Wik E, Birkeland E, Krakstad C, Kusonmano K, Petersen K, Kalland KH, Oyan AM, Akslen LA, Trovik J, Salvesen HB. ARID1A loss is prevalent in endometrial hyperplasia with atypia and low-grade endometrioid carcinomas. Mod Pathol. 2013; 26:428-434. 
39. Trovik J, Wik E, Stefansson IM, Marcickiewicz J, Tingulstad S, Staff AC, Njolstad TS, MoMaTec Study G, Vandenput I, Amant F, Akslen LA, Salvesen HB. Stathmin overexpression identifies high-risk patients and lymph node metastasis in endometrial cancer. Clin Cancer Res. 2011; 17:3368-3377.

40. Krakstad C, Tangen IL, Hoivik EA, Halle MK, Berg A, Werner HM, Raeder MB, Kusonmano K, Zou JX, Oyan AM, Stefansson I, Trovik J, Kalland KH, et al. ATAD2 overexpression links to enrichment of B-MYB-translational signatures and development of aggressive endometrial carcinoma. Oncotarget. 2015; 6:28440-28452. doi: 10.18632/oncotarget.4955.

41. Engelsen IB, Stefansson I, Akslen LA, Salvesen HB. Pathologic expression of $\mathrm{p} 53$ or p16 in preoperative curettage specimens identifies high-risk endometrial carcinomas. American journal of obstetrics and gynecology. 2006; 195:979-986.

42. Kononen J, Bubendorf L, Kallioniemi A, Barlund M, Schraml P, Leighton S, Torhorst J, Mihatsch MJ, Sauter G, Kallioniemi OP. Tissue microarrays for high-throughput molecular profiling of tumor specimens. Nat Med. 1998; 4:844-847.

43. Cuzick J, Swanson GP, Fisher G, Brothman AR, Berney DM, Reid JE, Mesher D, Speights VO, Stankiewicz E, Foster CS,
Moller H, Scardino P, Warren JD, et al. Prognostic value of an RNA expression signature derived from cell cycle proliferation genes in patients with prostate cancer: a retrospective study. Lancet Oncol. 2011; 12:245-255.

44. Lamb J, Crawford ED, Peck D, Modell JW, Blat IC, Wrobel MJ, Lerner J, Brunet JP, Subramanian A, Ross KN, Reich M, Hieronymus H, Wei G, et al. The Connectivity Map: using gene-expression signatures to connect small molecules, genes, and disease. Science. 2006; 313:1929-1935.

45. Cancer Genome Atlas Research N. Comprehensive molecular characterization of clear cell renal cell carcinoma. Nature. 2013; 499:43-49.

46. Hennessy BT, Lu Y, Gonzalez-Angulo AM, Carey MS, Myhre S, Ju Z, Davies MA, Liu W, Coombes K, MericBernstam F, Bedrosian I, McGahren M, Agarwal R, et al. A Technical Assessment of the Utility of Reverse Phase Protein Arrays for the Study of the Functional Proteome in Nonmicrodissected Human Breast Cancers. Clin Proteomics. 2010; 6:129-151.

47. Akbani R, Ng PK, Werner HM, Shahmoradgoli M, Zhang F, Ju Z, Liu W, Yang JY, Yoshihara K, Li J, Ling S, Seviour EG, Ram PT, et al. A pan-cancer proteomic perspective on The Cancer Genome Atlas. Nat Commun. 2014; 5:3887. 